\title{
Larvicidal potential of two silver nano- particles (Moringa oleifera and Ficus exasperata) against laboratory and field strains of Anopheles gambiae (Diptera: Culicidae) in Lagos, Nigeria
}

Emmanuel Taiwo Idowu ${ }^{1 *}$, Adedapo O. Adeogun 2,3, Luqman A. Adams ${ }^{4}$, Modupe A. Yusuf ${ }^{1}$, Olawale W. Salami ${ }^{1}$, Olakiigbe Abiodun Kanmi ${ }^{2}$, Joseph A. Bello ${ }^{5}$, Ifeoluwa Kayode Fagbohun', Olubunmi Adetoro Otubanjo and Taiwo Samson Awolola²

\begin{abstract}
Background: The interest in larvicides of plant origin is generally renewed in vector control because of their safety compared to synthetic larvicides. However, there are concerns about the relative safety dose of these phytochemicals on non-target organisms which led to the development of plant derived nanoparticles. In this study, we examined the bioefficacy of low doses of two green synthesized nanoparticles on immature stages of Anopheles mosquitoes in Nigeria. Aqueous plants (Moringa oleifera and Ficus exasperata) extracts were used in the biosynthesis. The prepared Ag-NPs were characterizations using Fourier-transform infrared spectroscopy (FT-IR), UVVis spectroscopy, and scanning electron microscopy (SEM). Third and early fourth instars of known susceptible laboratory strains of Anopheles gambiae s.s. (KISUMU strains) and pyrethroid resistant field strain of An. gambiae were exposed to serial dilutions of $0.25,0.5,0.75,1.0$ and $2.5 \mathrm{ppm}$ of each phyto nanoparticles. Moribund and dead larvae were observed after 24 and $48 \mathrm{~h}$ post exposure, and the results were analysed with descriptive statistics.

Results: With the laboratory mosquitoes, Moringa oleifera AgNP effected high mortalities of $88-100 \%\left(\mathrm{LC}_{50}=0.39\right.$ ppm; $\left.\mathrm{LC}_{95}=0.62 \mathrm{ppm}\right)$ at $24 \mathrm{~h}$ post exposure except at the lowest concentration, while Ficus exasperate AgNP induced a 32-100\% mortality $\left(\mathrm{LC}_{50}=0.51 \mathrm{ppm} ; \mathrm{LC}_{95}=1.15 \mathrm{ppm}\right)$ except at the lowest concentration. In the field populations, mortality in Moringa oleifera and Ficus exasperata was $23-93 \%\left(\mathrm{LC}_{50}=0.65 \mathrm{ppm} ; \mathrm{LC}_{95}=2.28 \mathrm{ppm}\right)$ and $37-50 \%\left(\mathrm{LC}_{50}=1.51 \mathrm{ppm} ; \mathrm{LC}_{95}=391.64 \mathrm{ppm}\right)$ respectively. There was no significant difference in mortality values between the laboratory and field strains $(P<0.05)$ at both 24 and $48 \mathrm{~h}$ post exposure times.

Conclusions: Overall, the study demonstrates the bioefficacy and potential use of green synthesized nanoparticles, at very low concentrations for the control of Anopheles larvae even in areas where resistance to the current chemical insecticides have been reported.
\end{abstract}

Keywords: Silver nano-particle larvicides, Laboratory and field strains, Anopheles gambiae, Nigeria

\footnotetext{
* Correspondence: etidowu@gmail.com; eidowu@unilag.edu.ng

'Department of Zoology, University of Lagos, Akoka, Yaba, Lagos, Nigeria

Full list of author information is available at the end of the article
}

\section{Springer Open}

( ) The Author(s). 2021 Open Access This article is licensed under a Creative Commons Attribution 4.0 International License, which permits use, sharing, adaptation, distribution and reproduction in any medium or format, as long as you give appropriate credit to the original author(s) and the source, provide a link to the Creative Commons licence, and indicate if changes were made. The images or other third party material in this article are included in the article's Creative Commons licence, unless indicated otherwise in a credit line to the material. If material is not included in the article's Creative Commons licence and your intended use is not permitted by statutory regulation or exceeds the permitted use, you will need to obtain permission directly from the copyright holder. To view a copy of this licence, visit http://creativecommons.org/licenses/by/4.0/. 


\section{Background}

The relative importance of mosquitoes in disease transmission has made them the target of several life cycle control activities including chemical, non-chemical and/ or biological control (WHO, 2017a).

The four classes of chemical-based control are Pyrethroids, Organophosphates, Organochlorines and Carbamates (Mazzarri \& Georghiou, 1995) which are quite impactful when deployed (WHO, 2017a); however, their drawback is the emerging development of resistance in mosquito species (Liu, 2015). Since 2010, a total of 60 countries have reported resistance to at least one class of insecticide, with 49 of those countries reporting Anopheles resistance to two or more classes (WHO, 2017a). Larval control is a complement to major vector control interventions such as the use of long-lasting insecticidetreated nets (LLINs) and indoor residual spray (IRS) (Killeen, Fillinger, \& Knols, 2002; WHO, 2017b). The concerns over chemical larvicides (physiological resistance by vectors, adverse environmental effects, high operational cost and community acceptance) necessitate sourcing for improved eco-friendly agents. Furthermore, malaria vector resistance to permethrin and deltamethrin has been reported in various parts of Lagos State (Awolola et al., 2018; Fagbohun, Oyeniyi, Idowu, Otubanjo, \& Awolola, 2019; Oduola et al., 2012). On this note, plant extracts have in some cases found interesting use as mosquito repellents (Samidurai, Jebanesan, Saravanakumar, Govindarajan, \& Pushpanathan, 2009), and for the management of larvae or adult mosquitoes (Ghosh, Chowdhury, \& Chandra, 2012; Interior Health, 2009). While the confinement provided by larval sites contributes to the potency of phytochemicals, concerns however exist on the dosage and relative toxicity for programmatic control. To improve the efficacy of the larvicides, nanoparticles are incorporates as delivery agents, particularly with sizes of $10-1000 \mathrm{~nm}$, thereby making the larvicides more powerful even at low doses (Mondal et al., 2014).

Several biosynthetic pathways to AgNPs using biomass extracts of Citrus limon (Mohapatra, Kaintura, Singh, Kuriakose, \& Mohapatra, 2015), Parthenium hysterophorus (Mondal et al., 2014), Thevetia peruviana (Oluwaniyi et al., 2016), Ocimum sanctum (Singhal, Bhavesh, Kasariya, Sharma, \& Singh, 2011) and pineapple leaf (Elemike et al., 2014) have been reported. Meanwhile, larvicidal activities of AgNPs using different plant extracts such as Agaricus bisporus (Dhanasekaran \& Thangaraj, 2013), Agave sisalana (Nunes et al., 2015), Azadirachta indica (Neem) (Soni \& Prakash, 2014), Delphinium denudatum (Suresh et al., 2014), Feronia elephantum (Veerakumar, Govindarajan, Rajeswary, \& Muthukumaran, 2014), Ficus racemosa (Velayutham, Rahuman, Rajakumar, et al., 2013), Morinda tinctoria
(Kumar, Nattuthurai, Gopinath, \& Mariappan, 2014) and Sterculia foetida L. (Rajasekharreddy \& Rani, 2014) have been reported against different larvae stages of Culex quinquefasciatus, Anopheles stephensi and Aedes aegypti. Hitherto there has been no report on the biosynthesis of AgNPs using Ficus exasperata. In the present study, we report the biosynthesis of silver nanoparticles using the aqueous extracts of Moringa oleifera and Ficus exasperate and their larvicidal potential explored against laboratory and suspected resistant field strains of Anopheles gambiae mosquitoes in Lagos Nigeria.

\section{Methods}

\section{Preparation of plant extracts}

The taxonomic identification of freshly collected leaves of Moringa oleifera family Moringaceae and Ficus exasperata family Moraceae were done at the Herbarium, Department of Botany, University of Lagos, Lagos, Nigeria. Thereafter, after thoroughly washing the leaves with distilled water and drying with paper absorbents, $40 \mathrm{~g}$ of leaves was soaked in 400-ml distilled water for 5 min before boiling for $15 \mathrm{~min}$, allowed to cool and filtered through Whatman-1 filter paper. The filtrate was kept refrigerated until further use (Nilanjuna, Samrat, \& Piyali, 2014).

\section{Synthesis of silver nanoparticles $\left(\mathrm{AgNO}_{3}\right)$}

Three hundred millilitres of distilled water was added to $2.54 \mathrm{~g}$ of silver nitrate and stirred to give $(0.05 \mathrm{M})$ silver nitrate solution. The solution was stirred with a magnetic stirrer for $5 \mathrm{~min}$ during the addition of $20 \mathrm{ml}$ of the plant extract and observed for colour change. The initial pale yellow colour of the mixture changed to dark brown after $72 \mathrm{~h}$ indicating the reduction from $\mathrm{Ag}^{+}$to $\mathrm{Ag}^{0}$. The resulting mixture was centrifuged at $4000 \mathrm{rpm}$ for $20 \mathrm{~min}$. The supernatant was discarded and the residue was oven dried at $70{ }^{\circ} \mathrm{C}$ to afford the silver nanoparticles as a brownish powder (Umoren, Obot, \& Gasem, 2014).

\section{Characterization of silver nanoparticles $\left(\mathrm{AgNO}_{3}\right)$}

Evaluation of the chemical composition of the surface of the silver nanoparticles and the molecular environment of the capping agents were performed using Fourier transform infrared spectroscopy (FTIR) with attenuated total reflectance (Bruker- tensor 27) operating in the wavenumber range of $4000-500 \mathrm{~cm}^{-1}$. The microstructure of the samples were evaluated in a scanning electron microscope (SEM) (Quanta 200 FEG model) equipped with an electron probe microanalyzer system. The samples were attached to a sample holder via carbon adhesive before being observed at an accelerating voltage of $15 \mathrm{kV}$. Absorbance values were measured by a UV-Vis spectrophotometer (Varian cary 50 Bio UV-VIS spectrophotometer). 


\section{Collection of field Anopheline mosquitoes}

Laboratory bred Anopheles gambiae s.s. (KISUMU strains) were taken from insectary at Nigerian Institute of Medical Research, Yaba, Lagos. This mosquito colony has been maintained at the insectary for over 10 years and known to be susceptible to all classes of insecticide. Field Anopheles mosquitoes, however, were collected from areas where resistant Anopheline populations have been reported in and around Lagos State (Adeogun, Popoola, Oduola, Olakiigbe, \& Awolola, 2017; Awolola, Oduola, Obansa, Chukwurah, \& Unyimadu, 2007; Oduola et al., 2012) and kept under standard insectary condition $\left(25-29{ }^{\circ} \mathrm{C} ; 78-82 \%\right.$ relative humidity). All the field Anopheline samples collected were identified morphologically using the standard taxonomic key (Gillies \& Coetzee, 1987).

\section{Determination of larvicidal activities of the silver} nanoparticles of Moringa oleifera and Ficus exasperata against Anopheles gambiae complex

Twenty-five late third instars of Anopheles mosquito larva were released into $100-\mathrm{ml}$ distilled water containing a mixture of nanoparticles at different doses 0.25 ppm, $0.5 \mathrm{ppm}, 0.75 \mathrm{ppm}, 1.0 \mathrm{ppm}$ and $2.5 \mathrm{ppm}$, each in four replicates. A total of 100 larvae in four replicates were kept in 100-ml water without phyto-nanoparticles (used as control). Larval mortality was observed every $10 \mathrm{~min}$ for $1 \mathrm{~h}$ for immediate mortality and then observed for $24 \mathrm{~h}$ and $48 \mathrm{~h}$ post exposure. Lethal concentration that killed $50 \%$ and $90 \%$ of the mosquito larva $\left(\mathrm{LC}_{50}\right.$ and $\left.\mathrm{LC}_{90}\right)$ was determined using Probit regression analysis with the statistical software package (SPSS).

\section{Result}

Fourier transform infrared spectroscopy analysis of the AgNPs

Surface characterisation and functionalities of the AgNPs were evaluated using Fourier transform infrared spectroscopy. The available functionalities provide insight into the viability of the suspected capping agents to achieve reduction of the silver ions to afford the silver nanoparticles. The FTIR spectra of silver nanoparticles displayed diagnostic peaks in Fig. 1, initially as a poorly resolved peak centered around $1010 \mathrm{~cm}^{-1}$ assigned to $\mathrm{C}-\mathrm{N}$ stretching of the amine, at $1542 \mathrm{~cm}^{-1} \mathrm{~N}-\mathrm{H}$ bending of amide, the broad band at $3500-2900 \mathrm{~cm}^{-1}$ is due to bounded hydroxyl $(-\mathrm{OH})$ or amine group $(-\mathrm{NH})$ and aliphatic $(-\mathrm{CH})$. Also, the peak centered around 1626 $\mathrm{cm}^{-1}$ was assigned to carboxyl group $(-\mathrm{C}=\mathrm{O})$ stretching vibration, while bands at $1000 \mathrm{~cm}^{-1}$ may be attributed to $\mathrm{C}-\mathrm{O}$ stretching vibrations.

In Fig. 2, the broad absorption central around 3500 to $2600 \mathrm{~cm}^{-1}$ may be attributed to $\mathrm{O}-\mathrm{H}$ stretching vibration, at $1277 \mathrm{~cm}^{-1} \mathrm{O}-\mathrm{H}$ bending vibrations, while bands at 1752 and $1641 \mathrm{~cm}^{-1}$ are characteristic of carboxyl group $(-\mathrm{C}=\mathrm{O})$ stretching vibrations, at $1551 \mathrm{~cm}^{-1} \mathrm{~N}-\mathrm{H}$ bending of amide, similarly bands indicating the presence of hydroxyl groups at 950 to $1030 \mathrm{~cm}^{-1}$ may be attributed to $\mathrm{C}-\mathrm{O}$ stretching vibrations (Badri \& Natarajan, 2010; Maria et al., 2007; Thirumurgan, Tomy, Jai Ganesh, \& Gobikrishnan, 2010).

\section{UV-Vis spectroscopy analysis of AgNPs}

The absorption spectra of silver nanoparticles synthesized from Moringa oleifera and Ficus exasperata extracts are shown in Fig. 3, and furthermore providing information on the sizing characteristics. The UV-Vis absorption maxima were obtained at 430 and $440 \mathrm{~nm}$ for Moringa oleifera and Ficus exasperata respectively. The bands are attributed to the surface plasmon resonance of AgNPs formed by reduction of aqueous $\mathrm{Ag}$ ions (Ali et al., 2015).

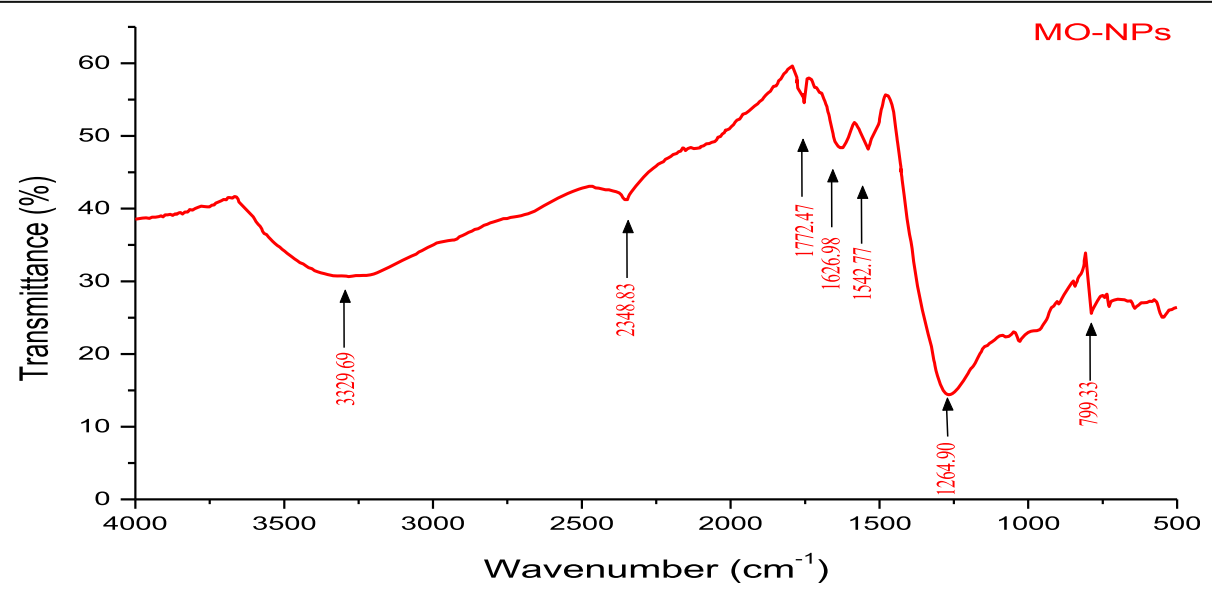

Fig. 1 Fourier transform infrared spectroscopy (FTIR) spectra of silver nanoparticles synthesized from M. oleifera leaf extract 


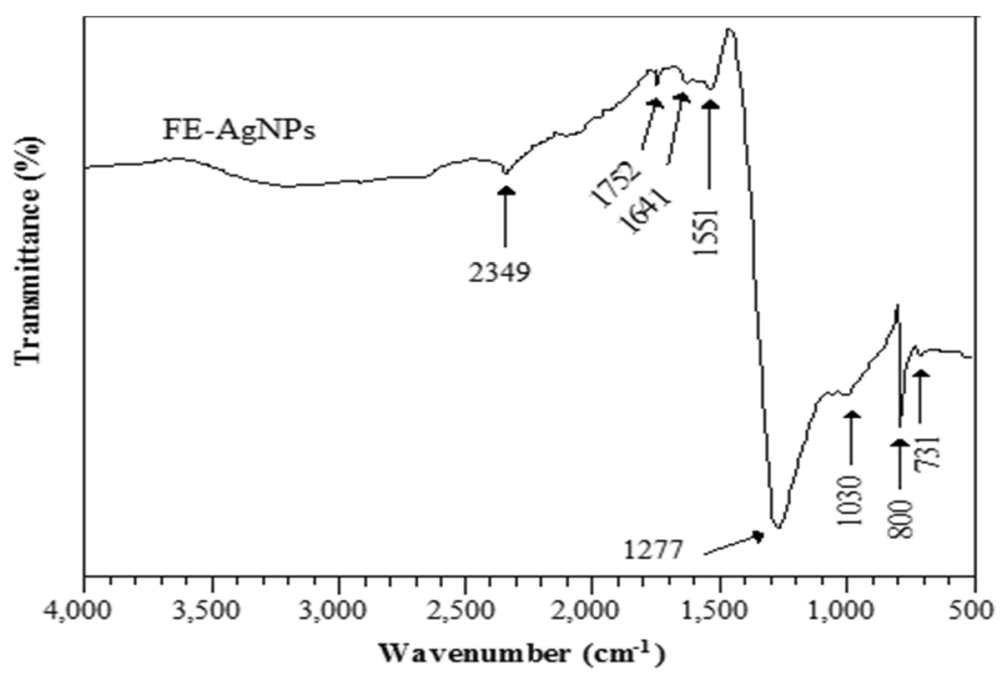

Fig. 2 Fourier transform infrared spectroscopy (FTIR) spectra of silver nanoparticles synthesized from F. exasperata extract

\section{Morphology of synthesised AgNPs}

The SEM micrographs of the silver nanoparticles which are presented in Fig. 4a and b provides information on the morphological pattern of the as prepared MOAgNPs and FE-AgNPs respectively. Analysis of the micrographs shows that the morphologies are characterized by closely packed particles that are well distributed to give homogeneous surfaces of small pore sizes. The unit sizes for both MO-AgNPs and FE-AgNPs were as small as $500 \mathrm{~nm}$ which are shown in the red circle on the SEM and in the particle size distribution chart in Fig. 5. It is evident that the smaller particles formed larger aggregates of about $500 \mathrm{~nm}$ during the biosynthesis. The results obtained confirm that plant extracts can effectively control the shape and size of the AgNPs.

Figure 6 shows the 3-D plots of the AgNPs surface morphology. The aggregation characteristics of the NPs show a more even distribution in the MO-NPs compared to the FE-NPs. The surface of the FE-NPs shows larger relative particle sizes and thus provides larger pore spaces.

\section{Larvicidal activity}

The laboratory strains of Anopheles, KISUMU strains, used for this work are known to be susceptible to all classes of insecticides and were all Anopheles gambiae s.s. A total of 1400 field samples were used in the study were all identified as members of the Anopheles gambiae s.l. The results of the larvicidal activities of Moringa oleifera and Ficus exasperata phyto-nanoparticles are shown in Fig. 7. Mortality rate appears to be dose dependent with the percentage mortality increasing with dose and time of exposure. Laboratory mosquitoes were more sensitive to the effect of the nanoparticles than the field

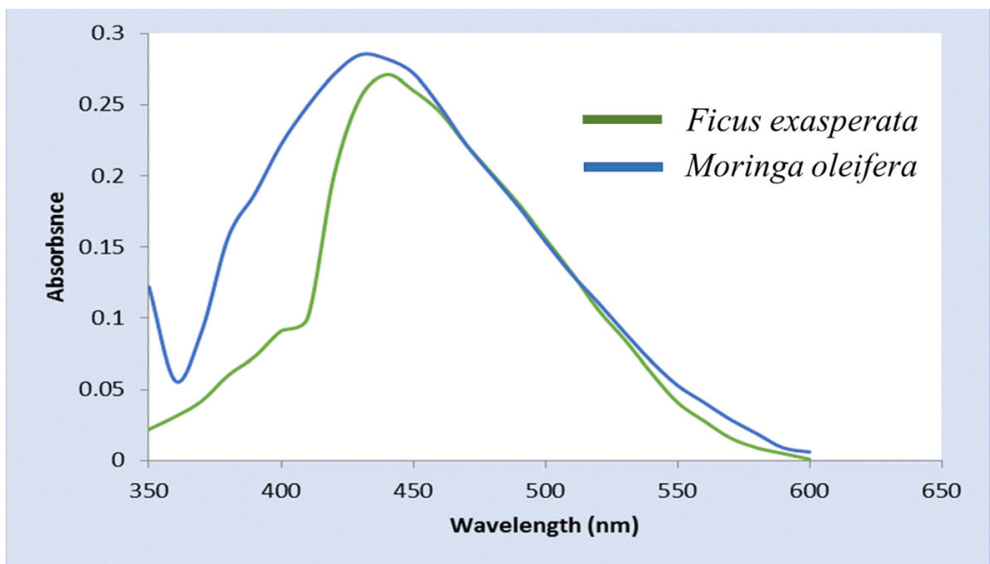

Fig. 3 UV-Vis absorption spectra of silver nanoparticles synthesized by Moringa oleifera (blue line) and Ficus exasperata (green line) 

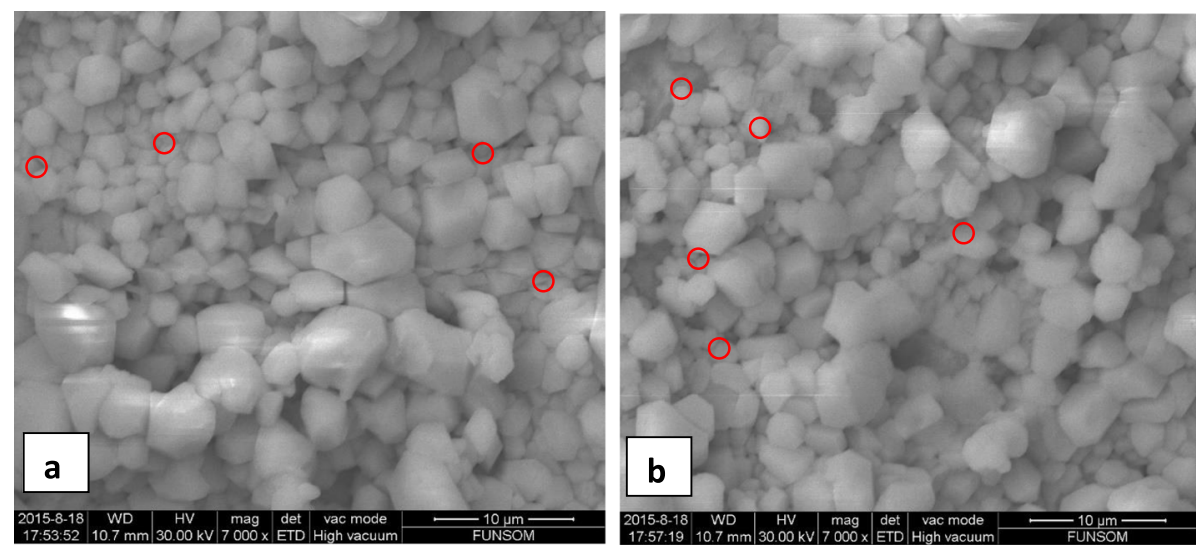

Fig. 4 SEM micrographs of the synthesized silver nanoparticles using plant extracts of a Moringa oleifera and $\mathbf{b}$ Ficus exasperata

strains (Fig. 7). In the laboratory mosquitoes, higher mortality $(88-100 \%)$ was observed from $0.5 \mathrm{ppm}$ for Moringa oleifera while for Ficus exasperate, mortality was (32-100\%) was observed at a slightly higher concentration of $0.75 \mathrm{ppm}$ at the $24 \mathrm{~h}$ and $48 \mathrm{~h}$ post exposure. However, with the field collected mosquitoes, Moringa oleifera, 23-93\% mortality; Ficus exasperata, 37-50\% at the same concentrations (Fig. 7).

The $\mathrm{LC}_{50}$ and $\mathrm{LC}_{95}$ values of the synthesized nanoparticles followed the same trend as the mortality values. At the $24 \mathrm{~h}$ post exposure period, 0.39 and $0.6 \mathrm{ppm}$ of Moringa oleifera were required to kill $50 \%$ and $95 \%$ of the laboratory mosquitoes while relatively higher concentrations of 0.65 and $2.28 \mathrm{ppm}$ were required to kill the field collected mosquitoes respectively. As for Ficus exasperata, the $\mathrm{LC}_{50}$ and $\mathrm{LC}_{95}$ concentrations were 0.51 and $1.15 \mathrm{ppm}$ and 1.51 and $391.64 \mathrm{ppm}$ for laboratory and field collected mosquitoes respectively (Table 1). In terms of bioactivity, it appears that Moringa oleifera tends to be more effective at lower concentrations as compared with Ficus exasperata. A comparison of the mortality values of the laboratory and field collected mosquitoes indicates no significant difference between the two at both $24 \mathrm{~h}$ and 48 h post exposure period $(P<0.05)$.

\section{Discussion}

The FTIR spectra of silver nanoparticles displayed diagnostic peak characteristics of the available functionalities that facilitated the reduction of the silver ions to afford the silver nanoparticles. Characteristic functionalities include amide, amine, hydroxyl, carbonyl of amide and aliphatics. The result of the surface functionality study is indicative of the presence of functional groups that are capable of reducing the silver ions as well as stabilization of the silver nanoparticles obtained in the form of capping agents. The UV-Vis spectroscopy provides details
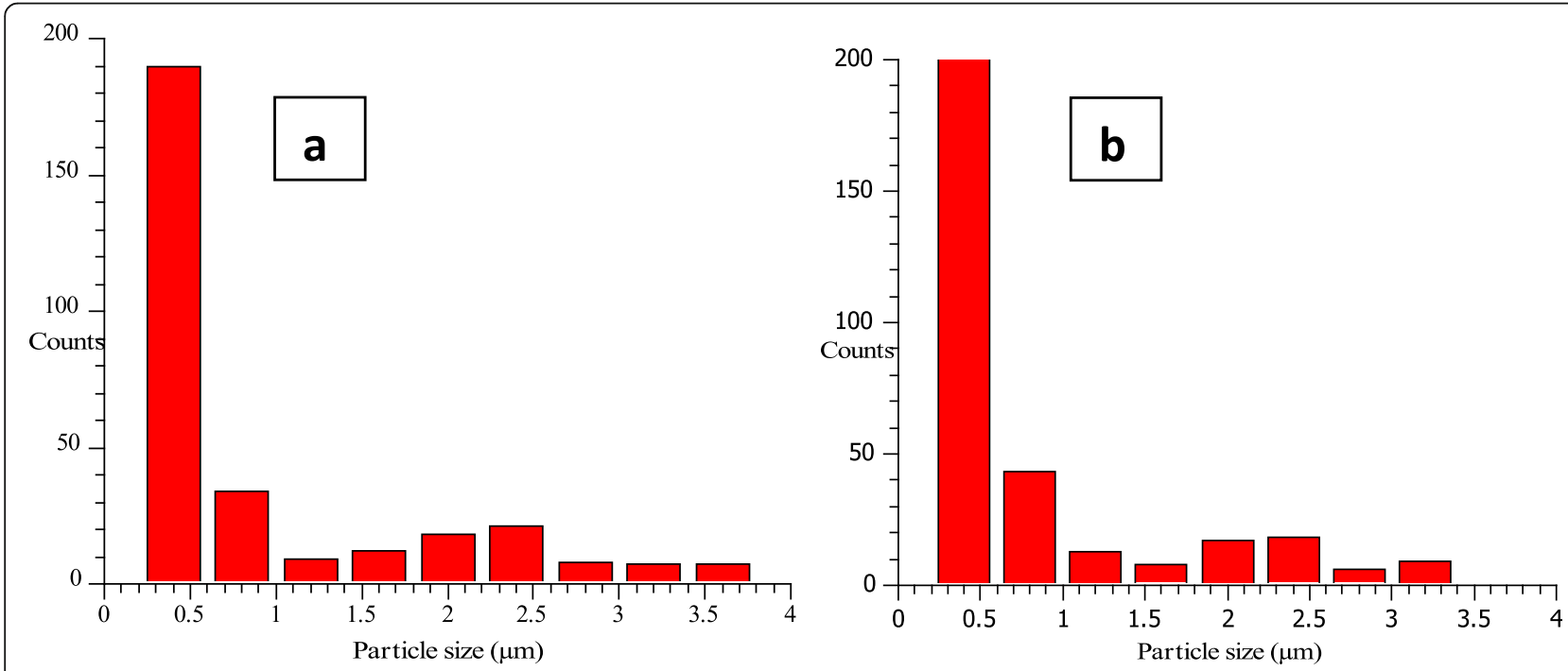

Fig. 5 Particle size distribution for the synthesized silver nanoparticles using plant extracts of a Moringa oleifera and $\mathbf{b}$ Ficus exasperata 

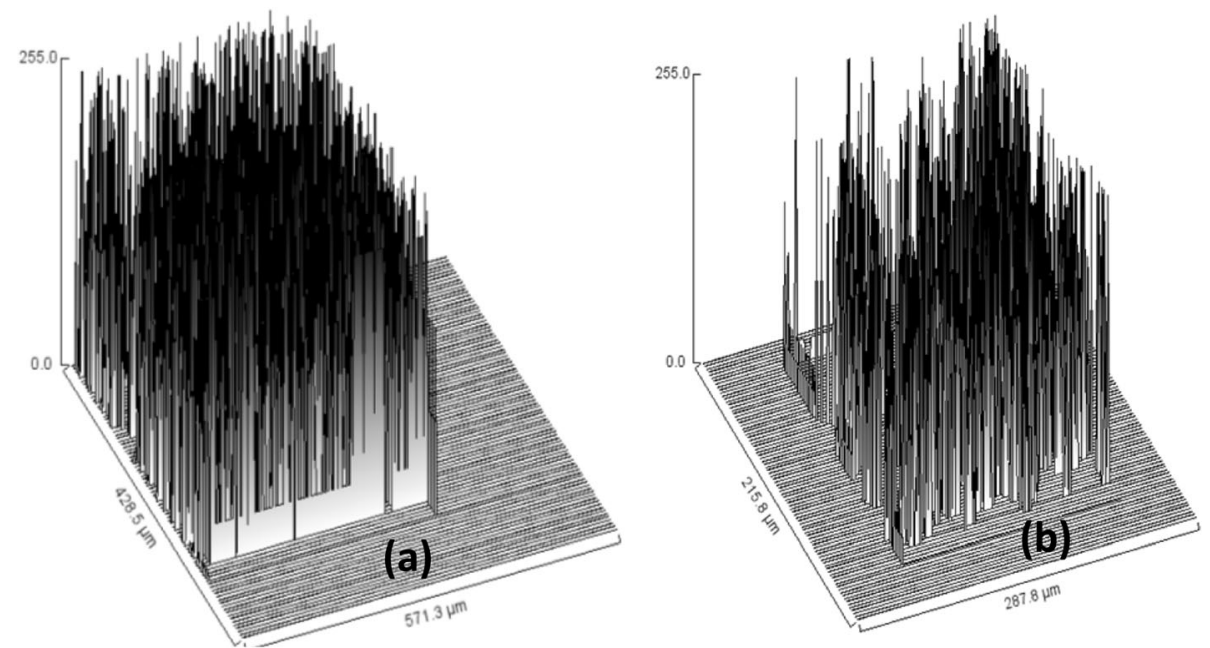

Fig. 6 3-D plots showing arrangement of particles on the surface of Moringa oleifera (a) and Ficus exasperata (b). Surface of the FE-AgNPs presents evidence of larger pore spaces

of the absorption maxima while the pattern can be used to make informed inference on the characteristics of the particle sizing. In this study, the absorption maxima were observed at 430 and $440 \mathrm{~nm}$ for Moringa oleifera and Ficus exasperata respectively. Apparently, they were not broad, thereby indicating a relatively narrow size range for the nanoparticles (Ali et al., 2015).

The average particle sizes were further elucidated using the software ImageJ. While the morphology of the particles are characterized by closed packing which are well distributed to give homogeneous surfaces of small pore sizes. The observed pattern is however influenced by a number of factors such as precursor and extract concentrations, incubation time and reaction temperature. It is also evident that nucleation of the smaller particles afforded the larger aggregates observed with size around $500 \mathrm{~nm}$. The MO-NPs were observed to be more evenly distributed relative to the FE-NPs.

Efforts at exploiting the potentials of plant derived substitute for chemical larvicides have yielded several phyto-chemicals with bioactivities against mosquitoes (Edriss, Satti, \& Alabjar, 2012; Kamaraj et al., 2011; Rathy, Sajith, \& Harilal, 2015). As compared with other larvicides, Moringa oleifera and Ficus exersperata have exhibited activity against Aedes aegypti, Culex quiquinfasciatus and Anopheles stephesis mosquitoes. In this regards, extracts of Moringa oleifera without AgNPs exhibited (Prabhu, Murugan, Nareshkumar, Ramasubramanian, \& Bragadeeswaran, 2011) $\mathrm{LC}_{50}$ and $\mathrm{LC}_{90}$ values ranging between 57.79 and $143.20 \mathrm{ppm}$. This may be partly due to the presence of Quercetin and kaempferol which have antioxidant properties with potential therapeutic uses (Pace-Asiak, Hahn, Diamandis, Soleas, \& Goldberg, 1995). Interestingly, a much reduced concentration of the phytochemicals with the introduction of AgNPs has been reported with a concentration range of 10.24-21.17 ppm for L1-Pupal samples of Aedes aegypti (Sijutha et al., 2015).

In this study, the efficacy of Moringa oleifera and Ficus exersperata at low concentrations could be adduced to the presence of the AgNPs. The mechanism by which this occurred could be the ability of the AgNPs to penetrate through larval membranes by binding to sulphurcontaining proteins or phosphorous containing compounds like DNA, leading to the denaturation of some organelles and enzymes (Rai, Yadav, \& Gade, 2009). Additionally, MO-AgNPs and FE-AgNPs killed most of the laboratory strains of Anopheles gambiae s.s. (KISUMU strains) at concentrations between 0.75 and 2.5 ppm with a higher range of 0.75 and $2.5 \mathrm{ppm}$ for $\mathrm{MO}$ AgNps and $2.5 \mathrm{ppm}$ for $\mathrm{FE}-\mathrm{AgNPs}$ respectively in the field strains. This is comparable with reports which also showed extremely low concentrations that fall within 1$30 \mathrm{mg} / \mathrm{l}$ (Dinesh et al., 2015; Rai et al., 2009; Rawani, Ghosh, \& Chandra, 2013). The result of this study can also be favourably compared with that of wild Indian almond tree, Sterculia foetida which showed $\mathrm{LC}_{50}$ values lower than $4.5 \mathrm{ppm}$ against Anopheles stephensi, Aedes aegypti, and Culex quinquinfasciatus (Rajasekharreddy \& Rani, 2014).

The reason for the differences between the laboratory mosquitoes and the field strains data is still not yet ascertained, but it is quite plausible to be the result of the insecticidal resistance of the field strains. Reports from this study area have showed that mosquito population are resistant to all classes of insecticide available for use in public health (Adeogun et al., 2017; Oduola et al., 2010, 2012). Though information on the use of 


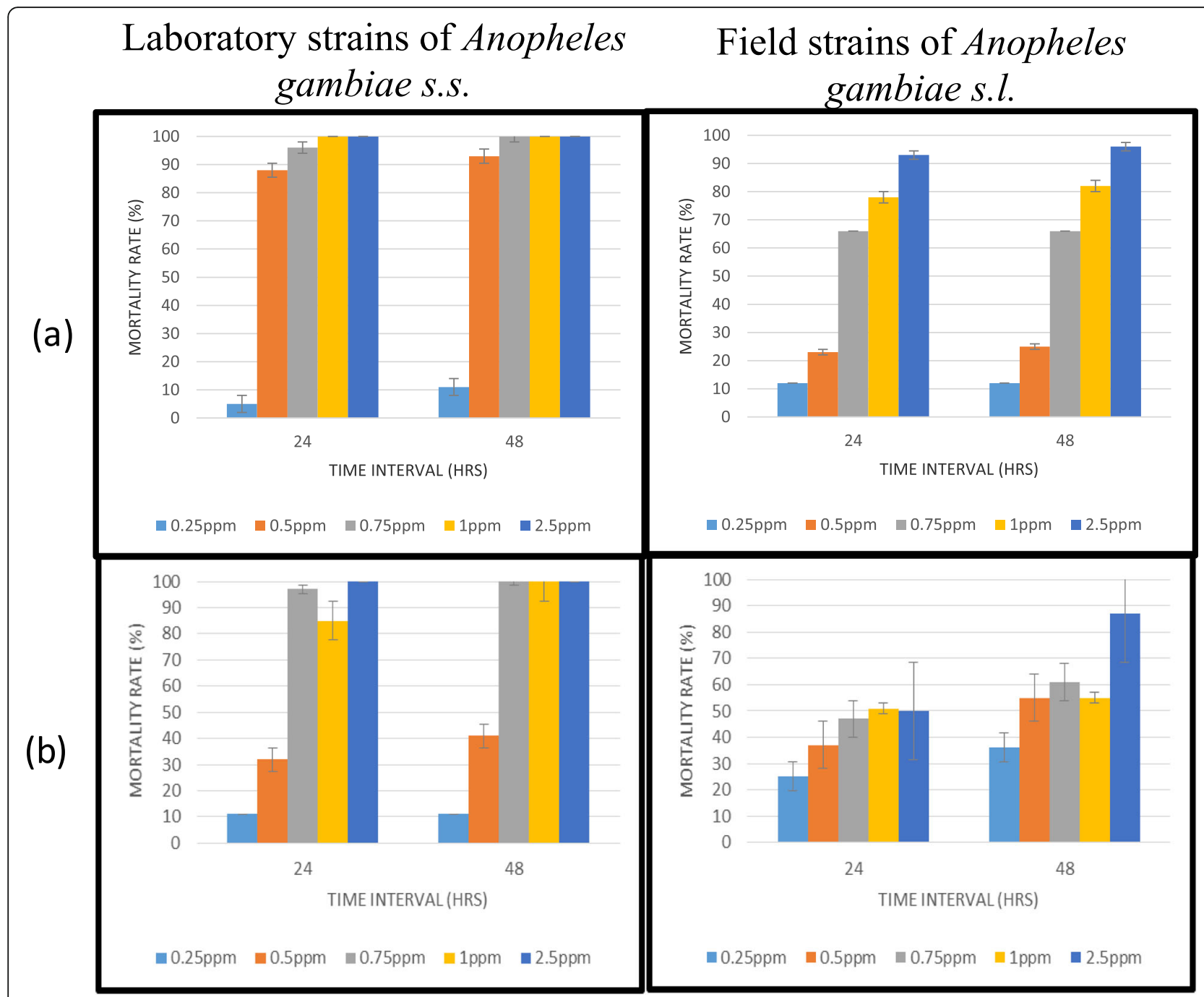

Fig. 7 Larval mortality of laboratory and field strains of Anopheles with synthesized AgNPs of a Moringa oleifera and $\mathbf{b}$ Ficus exasperata

phytochemicals for larval control from this area is not available, it is believed that the high level of insecticide resistance that has been reported in the populations of mosquitoes collected from the area might have had effect on the sensitivity of the mosquito populations at the initial stage of $24 \mathrm{~h}$ post exposure which decreased over time. Phytochemicals are known to have extended efficacy and usually have more than the "contact and kill" effect on insects; they show multiple effects which can reduce the longevity of the mosquitoes and expose them

Table 1 Larvicidal toxicity of synthesized (AgNPs) against field and laboratory strains of Anopheles gambiae

\begin{tabular}{|c|c|c|c|c|c|c|}
\hline \multirow[t]{2}{*}{ Extract+AgNP } & \multicolumn{3}{|l|}{$24 \mathrm{~h}$} & \multicolumn{3}{|l|}{$48 \mathrm{~h}$} \\
\hline & LC 50 (95\%C.L.) & LC 50 (95\%C.L.) & Slope \pm SE & LC 50 (95\%C.L.) & LC95 (95\%C.L.) & Slope \pm SE \\
\hline Moringa+AgNP(LS) & $0.39(0.30-0.45)$ & $0.62(0.50-1.00)$ & $3.26 \pm 0.27$ & $0.34(0.32-0.36)$ & $0.52(0.48-0.58)$ & $4.23 \pm 0.3$ \\
\hline Moringa+AgNP(FS & $0.65(0.40-1.01)$ & $2.28(1.33-15.37)$ & $0.56 \pm 0.08$ & $0.62(0.43-0.87)$ & $1.93(1.23-7.07)$ & $0.69 \pm 0.08$ \\
\hline$X^{2}$ (P value) & $15.0(0.24)$ & & & $10.04(0.27)$ & & \\
\hline Ficus+AgNP (LS) & $0.51(0.09-0.99)$ & $1.15(0.71-2.61)$ & $1.36 \pm 0.12$ & $0.45(0.18-0.75)$ & $0.82(0.56-19.61)$ & $2.21 \pm 0.18$ \\
\hline Ficus+AgNP (FS) & $1.51(1.01-3.53)$ & $391.64(47.89-500.29)$ & $-0.12 \pm 0.60$ & $0.49(0.13-0.83)$ & 8.58 (2.79-8.99) & $0.41 \pm 0.07$ \\
\hline$x^{2}$ (P value) & $20.0(0.22)$ & & & $6.67(0.35)$ & & \\
\hline
\end{tabular}

$P$ is significant at $P<0.05$

LS laboratory strain, FS field strain 
to adverse conditions and predation, and can also make resistance unlikely (Vatandoost \& Vaziri, 2004). This was believed to have been exhibited in these populations as the significant difference in mortality values between the laboratory and field collected mosquitoes decreased over time. Though we did not observe the population beyond $48 \mathrm{~h}$, it is possible for the values to decrease further and may later become insignificant indicating that insecticide resistance may not be a barrier to the efficacy of the nanoparticles.

\section{Conclusion}

We have reported herein the biosynthesis of AgNPs using aqueous extracts of Moringa oleifera and Ficus exersperata. The efficacy of the Moringa oleifera nanoparticles was higher at lower concentrations than that of Ficus exasperate on both the laboratory and field collected mosquitoes. Factors such as insecticide resistance in the field mosquito population do not appear to have effect on the efficacy of the two extracts as mortality increased with increase in time of exposure. This shows potentials of the nanoparticles for use as part of integrated approach towards the fight against mosquito vectors.

\section{Acknowledgements}

The authors will like to thank the laboratory technicians at the Department of Zoology, University of Lagos, and the Public Health and Epidemiology Division, Nigerian Institute of Medical Research, Yaba, Lagos, for their dedication towards this work.

\section{Declarations}

The content of this article is the sole responsibility of the author(s) and does not necessarily reflect the views or policies of anyone or organization.

\section{Authors' contributions}

IET, AOA, LAA, MAY, OWS and OAK carried out the field and laboratory studies; IET, OOA, LAA, AOA, JAB and ATS design and supervised the study; AOA, MAY, OWS and FIK carried out the data analysis and wrote the first manuscript draft; IET, JAB, OAT and OOA critically reviewed the manuscript. All authors read and approved the final manuscript.

\section{Funding}

No funding sources.

\section{Availability of data and materials}

Data generated during this study are included in this published article and also available upon request at the Vector research laboratory of Nigeria Institute of Medical Research (NIMR), Lagos.

\section{Ethics approval and consent to participate}

Not applicable.

\section{Consent for publication}

Not applicable.

\section{Competing interests}

The authors declared that there are no competing interests.

\section{Author details}

'Department of Zoology, University of Lagos, Akoka, Yaba, Lagos, Nigeria. ${ }^{2}$ Vector Research Unit, Nigeria Institute Medical Research, Yaba, Lagos, Nigeria. ${ }^{3}$ Department of Biological Sciences, Lead City University, Ibadan, Nigeria. ${ }^{4}$ Department of Chemistry, University of Lagos, Lagos, Nigeria.
${ }^{5}$ Department of Cell Biology and Genetics, University of Lagos, Lagos, Nigeria.

Received: 4 May 2020 Accepted: 21 December 2020

Published online: 09 January 2021

\section{References}

Adeogun, A. O., Popoola, K. O. K., Oduola, A. O., Olakiigbe, A. K., \& Awolola, T. S. (2017). High level of DDT resistance and reduced susceptibility to Deltamethrin in Anopheles gambiae, Anopheles coluzzi, and Anopheles arabiensis from Urban communities in Oyo State, South-West Nigeria. Journal of Mosquito Research, 7, 125-133.

Ali, K., Ahmed, B., Dwivedi, S., Saquib, Q., AlKhedhairy, A. A., \& Musarrat, J. (2015). Microwave accelerated green synthesis of stable silver nanoparticles with Eucalyptus globulus leaf extract and their antibacterial and antibiofilm activity on clinical isolates. PLoS One, 10, e0131178.

Awolola TS, Adeogun A, Olakiigbe AK, Oyeniyi T, Olukosi YA, Okoh H, et al. (2018). Pyrethroids resistance intensity and resistance mechanisms in Anopheles gambiae from malaria vector surveillance sites in Nigeria. PLoS One, 13 (12): e0205230. https://doi.org/10.1371/journal.pone.0205230.

Awolola, T. S., Oduola, O. A.r Obansa, J. B., Chukwurah, N. J., \& Unyimadu, J. P. (2007). Anopheles gambiae s.s. breeding in polluted water bodies in urban Lagos, Southwestern Nigeria. Journal of Vector Borne Diseases, 44, 241-244.

Badri, N. K., \& Natarajan, S. (2010). Biological synthesis of metal nanoparticles by microbes. Advances in Colloid and Interface Science, 156, 1-13.

Dhanasekaran, D., \& Thangaraj, R. (2013). Evaluation of larvicidal activity of biogenic nanoparticles against filariasis causing Culex mosquito vector. Asian Pacific Journal of Tropical Disease, 3, 174-179.

Dinesh, D., Murugan, K., Madhiyazhagan, P., Panneerselvam, C., Nicoletti, M., Jiang, W., ... Suresh, U. (2015). Mosquitocidal and antibacterial activity of greensynthesized silver nanoparticles from Aloe vera extracts: Towards an effective tool against the malaria vector Anopheles stephensi. Parasitology Research, 114, 1519-1529.

Edriss, A. E., Satti, A. A., \& Alabjar, Z. A. (2012). Preliminary studies on phytochemicals and larvicidal effects of Acacia nilotica L. extracts against Anopheles arabiensis Patton. Scientific Research and Essays, 7, 4253-4258.

Elemike, E. E., Oseghale, C. O., Chuku, A., Labulo, A. H., Owoseni, M. C., Mfon, R., .. Adesuji, E. T. (2014). Evaluation of antibacterial activities of silver nanoparticles green-synthesized using pineapple leaf (Ananas comosus). Micron, 57, 1-5.

Fagbohun, I. K., Oyeniyi, T. A., Idowu, T. E., Otubanjo, O. A., \& Awolola, S. T. (2019). Cytochrome P450 mono-oxygenase and resistance phenotype in DDT and deltamethrin-resistant Anopheles gambiae ( Diptera: Culicidae ) and Culex quinquefasciatus in Kosofe, Lagos, Nigeria. Journal of Medical Entomology, 56, 817-821. https://doi.org/10.1093/jme/tiz006.

Ghosh, A., Chowdhury, N., \& Chandra, G. (2012). Plant extracts as potential mosquito larvicides. The Indian Journal of Medical Research, 135, 581-598.

Gillies, M. T., \& Coetzee, M. (1987). A supplement to the Anophelinae of Africa south of the Sahara (Afro- An annotated checklist and bibliography of the mostropical Region). Johannesburg: South African Institute for Medical Research.

Interior Health, 2009. Pest management plan for control of mosquito larvae that are potential West Nile virus vectors.

Kamaraj, C., Bagavan, A., Elango, G., Zahir, A. A., Rajkumar, G., Mariamuthu, S., ... Rahuman, A. A. (2011). Larvicidal activity of medicinal plant extracts against Anopheles stephensi and Culex tritaeniorhynchus. The Indian Journal of Medical Research, 134, 101-106.

Killeen, G., Fillinger, U., \& Knols, B. G. J. (2002). Advantages of larval control for African malaria vectors: Low mobility and behavioural responsiveness of immature mosquito stages allow high effective coverage. Malaria Journal, 1, $1-8$.

Kumar, K. R., Nattuthurai, N., Gopinath, P., \& Mariappan, T. (2014). Synthesis of eco-friendly silver nanoparticles from Morinda tinctoria leaf extract and its larvicidal activity against Culex quinquefasciatus. Parasitology Research, 114, $411-417$.

Liu, N. (2015). Insecticide resistance in mosquitoes: Impact, mechanisms, and research directions. Annual Review of Entomology, 60, 537-559. https://doi. org/10.1146/annurev-ento-010814-020828.

Maria, C. S., Lourenço, V. N., de Souza, A. C., Pinheiro, M. L., Ferreira, R. S., et al. (2007). Evaluation of anti-tubercular activity of nicotinic and isoniazid analogues. In A Peraltab Gen. Pap., (vol. 15, pp. 181-191). 
Mazzarri, M. B., \& Georghiou, G. P. (1995). Characterization of resistance to organophosphate, carbamate, and pyrethroid insecticides in field populations of Aedes aegypti from Venezuela. Journal of the American Mosquito Control Association-Mosquito News, 11, 315-322.

Mohapatra, B., Kaintura, R., Singh, J., Kuriakose, S., \& Mohapatra, S. (2015). Biosynthesis of high concentration, stable aqueous dispersions of silver nanoparticles using Citrus limon extract. Advanced Materials Letters, 6, 228234.

Mondal, N. K., Chowdhury, A., Dey, U., Al, E., Mukhopadhya, P., Chatterjee, S., ... Datta, J. K. (2014). Green synthesis of silver nanoparticles and its application for mosquito control. Asian Pacific Journal of Tropical Disease, 4, 204-210.

Nilanjuna, G., Samrat, P., \& Piyali, B. (2014). Silver nanoparticles from Moringa Olifera green synthesis characterization and its antimicrobial efficacy. Journal of Drug Delivery and Therapeutics, 11, 20-25.

Nunes, F. C., Leite, J. A., Oliveira, L. H. G., Sousa, P. A. P. S., Menezes, M. C., Moraes, J. P. S., ... Braga, V. A. (2015). The larvicidal activity of Agave sisalana against L4 larvae of Aedes aegypti is mediated by internal necrosis and inhibition of nitric oxide production. Parasitology Research, 114, 543-549. https://doi.org/ 10.1007/s00436-014-4216-y.

Oduola, A. O., Idowu, E. T., Oyebola, M. K., Adeogun, A. A., Olojede, J. B., Otubanjo, O. A., \& Awolola, T. S. (2012). Evidence of carbamate resistance in urban populations of Anopheles gambiae s.s. Mosquitoes resistant to DDT and deltamethrin insecticides in Lagos. Parasites \& Vectors, 5, 1-9. https://doi.org/ 10.1186/1756-3305-5-116.

Oduola, A. O., Olojede, J. B., Ashiegbu, C. O., Olufemi, A., Otubanjo, O. A., \& Awolola, T. S. (2010). High level of DDT resistance in the malaria mosquito: Anopheles gambiae S. L. from rural, semi urban and urban communities in Nigeria. Journal of Rural and Tropical Public Health, 9, 114-120.

Oluwaniyi, O. O., Adegoke, H. I., Adesuji, E. T., Alabi, A. B., Bosede, S. O., Labulo, A. H., \& Oseghale, C. O. (2016). Biosynthesis of silver nanoparticles using aqueous leaf extract of Thevetia peruviana Juss and its antimicrobial activities. Applied Nanoscience, 6, 903. https://doi.org/10.1007/s13204-0150505-8

Pace-Asiak, C. R., Hahn, S., Diamandis, E. P., Soleas, G., \& Goldberg, D. M. (1995). The red wine phenolics trans-resveratrol and quercetin block human platelet aggregation and eicosanoid synthesis: implications for protection against coronary heart disease. Clinica Chimica Acta, 235, 207-219.

Prabhu, K., Murugan, K., Nareshkumar, A., Ramasubramanian, N., \& Bragadeeswaran, S. (2011). Larvicidal and repellent potential of Moringa oleifera against malarial vector, Anopheles stephensi Liston (Insecta: Diptera: Culicidae). Asian Pacific Journal of Tropical Biomedicine, 1, 124-129.

Rai, M., Yadav, A., \& Gade, A. (2009). Silver nanoparticles as a new generation of antimicrobials. Biotechnology Advances, 27, 76-83.

Rajasekharreddy, P., \& Rani, P. U. (2014). Biofabrication of Ag nanoparticles using Sterculia foetida L. seed extract and their toxic potential againstmosquito vectors and HeLa cancer cells. Materials Science and Engineering: C, 39, $203-$ 212.

Rathy, M. C., Sajith, U., \& Harilal, C. C. (2015). Larvicidal efficacy of medicinal plant extracts against the vector mosquito Aedes albopictus. International Journal of Mosquito Research, 2, 80-82.

Rawani, A., Ghosh, A., \& Chandra, G. (2013). Mosquito larvicidal and antimicrobial activity of synthesized nano-crystalline silver particles using leaves and green berry extract of Solanum nigrum L. (Solanaceae: Solanales). Acta Tropica, 128, 613-622.

Samidurai, K., Jebanesan, A., Saravanakumar, A., Govindarajan, M., \& Pushpanathan, T. (2009). Larvicidal, ovicidal and repellent activities of Pemphis acidult Frost (Lythraceae) against filarial and dengue vector mosquitoes. Academic Journal of Entomology, 2, 62-66.

Sijutha, V., Murugan, K., Paulpandi, M., Panneerselvam, C., Suresh, U., Roni, M., ... B.G (2015). Green synthesized silver nanoparticles as a novel control tool against dengue virus (DEN-2) and its primary vector Aedes aegypti. Parasitology Research, 10, 56-62. https://doi.org/10.1007/s00436-015-4556-2.

Singhal, G., Bhavesh, R., Kasariya, K., Sharma, A. R., \& Singh, R. P. (2011). Biosynthesis of silver nanoparticles using Ocimum sanctum (Tulsi) leaf extract and screening its antimicrobial activity. Journal of Nanoparticle Research, 13, 2981-2988.

Soni, N., \& Prakash, S. (2014). Silver nanoparticles: a possibility for malarial and filarial vector control technology. Parasitology Research, 113, 4015-4022

Suresh, G., Gunasekar, P. H., Kokila, D., Prabhu, D., Dinesh, D., Ravichandran, N., .. Silva, G. V. (2014). Green synthesis of silver nanoparticles using Delphinium denudatum root extract exhibits antibacterial andmosquito larvicidal activities. Spectrochimica Acta Part A: Molecular and Biomolecular Spectroscopy, 127, 61-66.

Thirumurgan, A., Tomy, N. A., Jai Ganesh, R., \& Gobikrishnan, S. (2010). Biological reduction of silver nanoparticles using plant leaf extracts and its effect an increased antimicrobial activity against clinically isolated organism. Der Pharma Chemica, 2, 279-284.

Umoren, S. A., Obot, I. B., \& Gasem, Z. M. (2014). Green sysnthesis of silver nanoparticles using apple (Malus domestica) fruit extract at room temperature. Journal of Materials and Environmental Science, 5, 907-914.

Vatandoost, H., \& Vaziri, V. M. (2004). Larvicidal activity of a neem tree extract (Neemarin) against mosquito larvae in the Islamic Republic of Iran. EMHJEastern Mediterranean Health Journal, 10(4-5), 573-581.

Veerakumar, K., Govindarajan, M., Rajeswary, M., \& Muthukumaran, U. (2014). Lowcost and eco-friendly green synthesis of silver nanoparticles using Feronia elephantum (Rutaceae) against Culex quinquefasciatus, Anopheles stephensi, and Aedes aegypti (Diptera: Culicidae). Parasitology Research, 113, 1775-1785.

Velayutham, K., Rahuman, A. A., Rajakumar, G., et al. (2013). Larvicidal activity of green synthesized silver nanoparticles using bark aqueous extract of Ficus racemosa against Culex quinquefasciatus and Culex gelidus. Asian Pacific Journal of Tropical Medicine, 6, 95-101.

WHO (2017a). Global vector control response 2017-2030. Geneva, World Health Organization.

WHO (2017b). Malaria vector control policy recommendations and their applicability to product evaluation. Geneva, World Health Organization.

\section{Publisher's Note}

Springer Nature remains neutral with regard to jurisdictional claims in published maps and institutional affiliations.

\section{Submit your manuscript to a SpringerOpen ${ }^{\odot}$ journal and benefit from:}

- Convenient online submission

Rigorous peer review

- Open access: articles freely available online

- High visibility within the field

- Retaining the copyright to your article

Submit your next manuscript at $>$ springeropen.com 